\title{
Suicide and the Dexamethasone Suppression Test
} in Adolescence

\author{
Douglas R. Robbins and Norman E. Alessi
}

The identification and treatment of adolescents at risk for suicide is one of the most critical issues in adolescent psychiatry. Suicide is the third leading cause of death in the age group and its prevalence appears to be rising (Holinger, 1978). Clinicians see many adolescents with suicidal thoughts or behavior, however, who are not all equally at risk for future lethal attempts. While demographic, diagnostic, and other clinical factors are helpful in identifying adolescents at risk for suicide (Carlson and Cantwell 1982; Garfinkle et al. 1982; Robbins and Alessi 1983) such factors remain limited in their ability to identify individuals at greatest risk (Pokorny 1983). A biological marker of current or future risk for suicide could be an important adjunct to the clinician confronting this dilemma. Furthermore, study of biological markers may help us towards an understanding of the neurophysiological substrates of severe dysphoric mood states.

Carroll (1982) has reported an association of nonsuppression in the dexamethasone suppression test (DST) with severe or lethal suicide attempts in adults. Three other groups also observed DST nonsuppression in patients hospitalized for suicide attempts or who subsequently

\footnotetext{
From the Department of Psychiatry, University of Michigan Medical Center, Ann Arbor, Michigan.

Address reprint requests to: Dr. Douglas R. Robbins, Adolescent Psychiatry, University of Michigan Hospital, Ann Arbor, Michigan 48109

Received January 18, 1984, revised July 6, 1984.
}

made lethal or potentially lethal attempts (Coryell and Schlesser 1982; Targum et al. 1983; Banki and Arato 1982). Others have reported high urinary free cortisol in lethal suicide attempts (Ostroff et al. 1983). CSF cortisol levels, however, did not distinguish suicidal patients in one earlier study (Bunney et al. 1969). This study presents preliminary observations of the DST as a possible biological correlate of suicide in adolescents.

\section{Method}

All adolescents (13-18 years) admitted to the inpatient unit of the University of Michigan Adolescent Psychiatry Service are evaluated by two child psychiatrists with the Schedule for Affective Disorders and Schizophrenia (SADS), Hamilton Depression Rating Scale, and Carroll Depression Self-Rating Scale, and all are given a diagnosis according to the Research Diagnostic Criteria (RDC) and DSM-III. All those not excluded for medical reasons are given a dexamethasone suppression test (DST), using $1 \mathrm{mg}$ oral dexamethasone at 11:30 PM on day 1 , with blood samples for cortisol at 11:00 on day 1 and at 8:00 AM, 4:00 PM, and 11:00 PM on day 2 . Cortisol is assessed by competitive protein binding radioimmunoassay (Pierson-Murphy 1967). Cortisol values over $5 \mu \mathrm{g} / \mathrm{ml}$ in any sample on day 2 are considered abnormal. In this population, the DST has been abnormal in $44 \%$ of those with Major Depressive Disorder, endogenous subtype, and in none with other diagnoses (Robbins et al. 1983). 
Suicide attempts and ideation are investigated in the clinical evaluation and the SADS interview. The SADS item for "Medical Lethality" of suicide attempts is defined as follows: 1 ("No danger... held pills in hand"), 2 ("Minimal, e.g., scratch on wrist"), 3 ("Mild, e.g., took 10 aspirins"), 4 ("Moderate ... brief unconsciousness"), 5 ("Severe, e.g., cuts throat"), 6 ("Extreme, e.g., respiratory arrest"). Attempts were rated as being medically dangerous if they received a rating of 4 to 6 on this SADS item.

\section{Results}

Of 45 adolescents evaluated, 23 had attempted suicide. The ages, sex, diagnoses, SADS Medical Lethality, and DST results are presented in Table 1. Of those with suicidal behavior, four made medically dangerous attempts (SADS Medical Lethality $=4-6$ ). The results are summarized by category of suicidal behavior and DST results in Table 2. All six of those with DST nonsuppression attempted suicide on admission, while 17 of the 22 with normal DSTs

Table 1. Age, Sex, Diagnosis, Suicidal Medical Lethality, and DST Results of Patients Attempting Suicide

\begin{tabular}{|c|c|c|c|c|c|c|c|c|}
\hline \multirow[b]{2}{*}{ Patient number } & \multirow[b]{2}{*}{ Age } & \multirow[b]{2}{*}{ Sex } & \multirow{2}{*}{$\begin{array}{c}\text { DSM Ill } \\
\text { Axis I Diagnosis }\end{array}$} & \multirow{2}{*}{$\begin{array}{c}\text { SADS } \\
\text { Medical Lethality }^{a}\end{array}$} & \multicolumn{4}{|c|}{ DST cortisol values } \\
\hline & & & & & 11:00 & $8: 00$ & $4: 00$ & $11: 00$ \\
\hline 1 & 17 & $\mathbf{M}$ & $\begin{array}{l}\text { MD-Mel } \\
\text { Atypical BPD }\end{array}$ & 5 & 1.72 & 1.37 & 1.55 & 7.49 \\
\hline 2 & 16 & $\mathbf{M}$ & MD-Mel & 6 & 2.15 & 18.42 & 5.61 & 2.43 \\
\hline 3 & 17 & $\mathbf{M}$ & MD-Mel & 5 & 11.42 & 7.03 & 7.19 & 4.58 \\
\hline 4 & 17 & $\mathrm{~F}$ & MD-Mel & 4 & 16.28 & 6.94 & - & 7.90 \\
\hline 5 & 16 & $\mathbf{M}$ & MD & 2 & 3.09 & 4.20 & 4.38 & 3.42 \\
\hline 6 & 14 & $\mathbf{M}$ & $\mathrm{MD}$ & 1 & 1.72 & 1.65 & 1.56 & 1.44 \\
\hline & & & $\begin{array}{r}\mathrm{CD} \text {, soc., } \\
\text { nonagg. }\end{array}$ & & & & & \\
\hline 7 & 13 & $\mathbf{F}$ & MD-Mel & 1 & 7.26 & 1.17 & 1.17 & 1.03 \\
\hline 8 & 16 & $\mathbf{M}$ & $\begin{array}{l}\text { MD } \\
\mathrm{O}-\mathrm{CD}\end{array}$ & 2 & 2.07 & 2.03 & 1.55 & 1.18 \\
\hline 9 & 16 & $\mathbf{F}$ & MD-Mel & 2 & 10.86 & 1.09 & 0.59 & 8.42 \\
\hline 10 & 16 & $\mathbf{M}$ & $\mathrm{DD}$ & 3 & 3.90 & 1.43 & - & 0.52 \\
\hline 11 & 14 & $\mathbf{F}$ & DD & 1 & - & 0.91 & 0.68 & 0.27 \\
\hline 12 & 16 & $\mathbf{M}$ & MD-Mel & 1 & 3.99 & - & 1.01 & 2.36 \\
\hline 13 & 14 & $\mathbf{F}$ & $\begin{array}{l}\text { MD-Mel } \\
\text { Psychotic }\end{array}$ & 1 & 1.11 & 1.11 & 1.34 & 0.92 \\
\hline 14 & 16 & $\mathbf{M}$ & $\mathrm{MD}$ & 3 & 1.09 & - & 1.90 & 1.55 \\
\hline 15 & 16 & $\mathrm{~F}$ & $\begin{array}{l}\text { MD-Mel } \\
\text { Atypical BPD }\end{array}$ & 2 & 2.48 & 8.54 & 1.16 & 1.39 \\
\hline 16 & 16 & $\mathbf{F}$ & $\mathrm{MD}$ & 2 & 0.72 & 0.43 & 0.34 & 0.68 \\
\hline 17 & 17 & $\mathbf{F}$ & S-P & 1 & 2.29 & 2.69 & 2.49 & 1.51 \\
\hline 18 & 16 & F & MD & 1 & 3.75 & 0.87 & 0.83 & 1.78 \\
\hline 19 & 14 & F & MD & 3 & 2.70 & 2.03 & 1.57 & 1.32 \\
\hline 20 & 16 & $\mathrm{~F}$ & MD-Mel & 2 & 3.00 & 1.48 & 1.20 & 1.42 \\
\hline 21 & 12 & $\mathbf{F}$ & $\begin{array}{r}\mathrm{CD} \text {, soc., } \\
\text { nonagg. }\end{array}$ & 1 & 2.31 & 3.73 & 3.06 & 2.87 \\
\hline 22 & 12 & $\mathbf{M}$ & MD & 3 & - & 0.58 & 0.64 & - \\
\hline 23 & 17 & $\mathbf{M}$ & S-P & 1 & 3.86 & 0.93 & 0.99 & 2.71 \\
\hline
\end{tabular}

"See text for definitions of SADS Medical Lethality ratings.

Atypical BPD $=$ Atypical Bipolar Disorder; $\mathrm{CD}=$ Conduct Disorder; $\mathrm{DD}=$ Dysthymic Disorder; $\mathrm{MD}=$ Major Depression; MD-Mel = Major Depression-Melancholic; nonagg. = nonaggressive; $\mathrm{O}-\mathrm{CD}=$ Obsessive-Compulsive Disorder; soc. = socialized; $\mathbf{S}-\mathbf{P}=$ Schizophrenia-Paranoid. 
Table 2. Suicidal Behavior and DST Results

\begin{tabular}{ccc}
\hline & $\begin{array}{c}\text { DST } \\
\text { suppressors }\end{array}$ & $\begin{array}{c}\text { DST } \\
\text { nonsuppressors }\end{array}$ \\
\hline Suicidal behavior & 17 & 6 \\
Lethal attempt & 0 & 1 \\
Potentially lethal attempt & 0 & 3 \\
Nonlethal attempt & 17 & 2 \\
No suicidal behavior & 22 & 0 \\
\hline
\end{tabular}

had attempted suicide. The association of suicide attempts with DST nonsuppression was significant $\left(\chi^{2}=6.622\right.$, df $\left.=1, p<0.01\right)$.

Of those who attempted suicide, four of the six nonsuppressors made medically dangerous or lethal attempts, while none of the 17 suppressors made such severe attempts. This statistic suggests a highly significant association of DST nonsuppression with lethal or potentially lethal suicidal behavior $\left(\chi^{2}=13.719, \mathrm{df}=1\right.$, $p<0.0002$ ).

It should be noted that two patients admitted for non-medically serious attempts were found to have nonsuppression, and subsequently made medically serious attempts-one fatal. The others making medically serious attempts had made those attempts just prior to admission.

\section{Discussion}

The number of adolescents studied is relatively small $(n=45)$ and must be replicated with a larger population, but these observations may have important implications. These observations extend to the critical adolescent age group the preliminary findings by others that there may be an identifiable dysfunction of the hypothalmic-pituitary-adrenal axis associated with severe dysphoric states in which individuals may be seriously suicidal (Carroll 1982; Coryell and Schlesser 1982; Targum et al. 1983; Ostroff et al. 1983; Banki and Arato 1982).

Because of the current controversy regarding the diagnostic specificity of the DST and because of the preliminary nature of all the reported associations of the DST with suicidal behavior, the clinical utility of these findings must be considered uncertain. They raise the possibility, however, that an abnormal DST may prove useful as a marker of increased potential for suicide. It should be noted that two subjects with nonsuppression on the DST initially made suicidal attempts that were medically not serious, but later went on to make serious attempts, one fatal; this suggests that the DST might identify individuals at higher risk at a point when clinical features alone would not so clearly identify them. Larger studies are clearly needed to establish whether such clinical applications are justified. Separately from the possible clinical utility of the marker, further study is needed to clarify whether or not the DST helps us understand the pathophysiology of severe dysphoric mood states.

\section{References}

Banki CM, Arato M, Papp Z, Kurcz M (1984): Biochemical markers in suicidal patients: Investigations with cerebrospinal fluid amine metabolites and neuroendocrine tests. J Affective Disord 6:341-350.

Bunney WE, Fawcett JA, Davis JM et al (1969): Further evaluation of urinary 17-hydroxy corticosteroids in suicide patients. Arch Gen Psychiatry 21:138-150.

Carlson GA, Cantwell DP (1982): Suicidal behavior and depression in children and adolescents. $J \mathrm{Am}$ Acad Child Psychiatry 21:361-368.

Carroll BJ (1982): The dexamethasone suppression test for melancholia. Br J Psychiatry 140:292-304.

Coryell W, Schlesser MA (1981): Suicide and the dexamethasone suppression test in unipolar depression. Am J Psychiatry 138:1120-1121.

Garfinkle BD, Froese A, Hood J (1982): Suicide attempts in children and adolescents. Am J Psychiatry 139:1257-1261.

Holinger PC (1978): Adolescent Suicide: An Epi- 
demiological Study of Recent Trends. Am J Psychiatry 135:754-756.

Ostroff R, Giller E, Gonese K, Ebersole E, Harkness L, Mason J (1983): Neuroendocrine risk factors of suicidal behavior. Am J Psychiatry 139:13231325.

Pierson-Murphy BE (1967): Some studies of protein binding steroids and their application to the routine micro and ultramicro measurement of various steroids in body fluids by competitive protein binding radioassay. $J$ Clinical Endocrinol Metab 27:973-990.
Pokorny AD (1983): Prediction of suicide in psychiatric patients. Arch Gen Psychiatry 40:249257.

Robbins DR, Alessi NE, Yanchyshyn GW, Colfer MV (1983): The dexamethasone suppression test in psychiatrically hospitalized adolescents. $J$ Am Acad Child Psychiatry 22 (5):467-469.

Targum SD, Rosen L, Capodanno AE (1983): The dexamethasone suppression test in patients with unipolar depression. Am J Psychiatry 140:877879.

\title{
Are There Antibodies Against Brain in Sera from Schizophrenic Patients? Review and Prospectus
}

\author{
Lynn E. DeLisi, Richard J. Weber, Candace B. Pert
}

\section{Introduction}

An autoimmune basis to neuropsychiatric disorders was first proposed during the early $1900 \mathrm{~s}$ (Khoroshko 1912). The subsequent search for circulating autoantibodies in sera and cerebrospinal fluid (CSF) from schizophrenic patients has resulted in numerous published reports, some of which confirm and others of which fail to find support for this hypothesis.

As early as 1937, Lehmann-Facius described evidence for the presence of circulating antibrain antibodies in sera from schizophrenic patients, specifically to antigens unique to post-

\footnotetext{
From the Section on Neurogenetics, National Institute of Mental Health, Bethesda, Maryland 20205; and the Section on Brain Biochemistry, National Instinute of Mental Health, Bethesda, Maryland 20205

Address reprint requests to: Dr. Candace B. Pert, National Institute of Mental Health, Bldg. 10, Rm. 3N256, 9000 Rockville Pike, Bethesda, Maryland 20205.

Received March 16, 1984.
}

mortem schizophrenic brain (Lehmann-Facius, 1937, 1939). Thirty years later, Heath et al. $(1967 \mathrm{a}, \mathrm{b})$ reported the partial purification of a substance (taraxein) present in sera from schizophrenic patients that, when injected in monkeys as well as in normal human volunteers, produced EEG and behavioral alterations analogous to those observed in schizophrenic patients. Since antibodies raised in sheep against human brain tissue injected into monkey cerebral ventricles produced similar EEG and behavioral changes, Heath proposed that taraxein could be an antibrain antibody. In addition, using a fluorescent antibody-staining technique in studies of schizophrenic and normal postmortem brain, Heath and Krupp (1967) demonstrated the presence of antibrain globulins in schizophrenic sera. Table 1 summarizes the salient features of a number of additional studies conducted by other investigators over the past two decades designed to detect antibrain antibodies in schizophrenic sera. 